\title{
O TRABALHO DE PARCERIA NA ESCOLA: implicações para a constituição docente.
}

\author{
Pamela Aparecida Cassão \\ Laura Noemi Chalub
}

\section{Resumo}

O presente trabalho é um recorte de uma pesquisa que tematizou o "trabalho de parceria" entre professora em exercício e bolsistas, graduandas do curso de pedagogia, no contexto escolar. Para ampliar a compreensão do trabalho docente pelo viés da colaboração e parceria, questão central da referida pesquisa, foi realizado um levantamento bibliográfico de periódicos na área de educação, no estrato A1 (QUALIS CAPES). Nesta produção problematizamos os artigos sistematizados a partir daquele mapeamento bibliográfico na tentativa de compreender os diferentes conceitos e entendimentos que circulam no meio acadêmico em relação à temática em questão. Entende-se que o trabalho de parceria considera a escola como propositora de processos formativos, pautados em relações de confiança e que, os sujeitos que participam, estejam abertos a dialogar e problematizar questões da vida educativa que compartilham assumindo sua responsabilidade e compromisso perante as decisões tomadas conjuntamente.

Palavras-chave: trabalho de parceria; formação de professores; cotidiano escolar.

\section{THE WORK OF PARTNERSHIP IN THE SCHOOL: implications for the Faculty constitution.}

\begin{abstract}
The present work is an excerpt from a research that focused on the "partnership work" between an active teacher and Pedagogy graduates with scholarship in the school context. In order to broaden the understanding of teaching work with the bias of collaboration and partnership, a central issue of the referred research, it was carried out a bibliographic survey of journals in the area of Education with quality stratum A1 (QUALIS CAPES). In that task, we problematized the systematized articles trying to understand the different concepts and the understandings that circulate in the academia, considering the issue in question. It is understood that the partnership work considers the school as a proponent of formative processes, based on relationships of trust and that the subjects who participate are open to dialogue and problematize issues of the educational life that they share, assuming their responsibility and commitment before the decisions taken together.
\end{abstract}

Keywords: partnership work; teacher training; school daily.

\section{EL TRABAJO ASOCIADO EN LA ESCUELA: implicaciones para la constitución docente.}

Resumen

El presente trabajo es un recorte de una investigación que tuvo como temática el "trabajo asociativo" entre una profesora en ejercicio y becarias, estudiantes de la licenciatura del curso de Pedagogía, en el contexto escolar. Para ampliar la comprensión del trabajo docente por el punto de vista de la colaboración y asociación, cuestión central de la referida investigación, fue realizado un levantamiento bibliográfico de periódicos en el área de Educación, en el estrato A1 (QUALIS CAPES). En esta producción problematizamos los artículos sistematizados a partir de ese mapeo bibliográfico buscando comprender los 
diferentes conceptos y entendimientos que circulan en el medio académico en relación a la temática en cuestión. Se entiende que el trabajo asociativo considera la escuela como proponente de procesos de formación pautados en relaciones de confianza y que, los sujetos que participan, estén abiertos a dialogar y problematizar cuestiones de la vida educativa que comparten asumiendo su responsabilidad y compromiso frente a las decisiones tomadas conjuntamente.

Palabras clave: trabajo asociativo; formación de profesores; cotidiano escolar.

\section{INTRODUÇÃO}

Este trabalho é um recorte de pesquisa ${ }^{1}$ (CASSÃO, 2019) que tematizou e problematizou a experiência vivida por uma professora em exercício junto com duas futuras professoras, bolsistas do Programa do Núcleo de Ensino da Universidade Estadual Paulista (UNESP), no contexto escolar. O referido programa iniciou no ano de 1987 tendo como objetivo aproximar universidade, escolas públicas e sociedade com a intencionalidade de trabalhar e refletir acerca dos problemas sociais.

A primeira autora deste trabalho, na época, professora em exercício, acolheu, ao longo de três anos (2014-2017), em sua sala de aula, duas professoras em formação inicial, semanalmente, com o intuito de juntas organizarem o trabalho pedagógico a partir de propostas vinculadas a dois projetos $^{1}$ e que tinham como objetivo promover experiências com a literatura de modo a potencializar e despertar a subjetividade e a construção de sentidos múltiplos.

Posteriormente, a professora da sala tomou como objeto de estudo essa experiência ao desenvolver uma investigação narrativa de experiências do vivido (LIMA, GERALDI, GERALDI, 2015 , p. 10) ${ }^{2}$. Segundo os referidos os autores, uma pesquisa narrativa só acontece quando "[...] havendo uma experiência significativa na vida do sujeito pesquisador, este a toma como objeto de compreensão". A produção dos dados foi desenvolvida a partir do paradigma indiciário (GINZBURG, 1989), na busca por pistas e indícios que permitissem ampliar a compreensão dos acontecimentos narrados.

A pesquisa de Cassão (2019), ao revelar uma experiência singular entre professora em exercício na sua relação com as bolsistas (professoras em formação), trouxe uma contribuição para o campo da formação de professores ao explicitar a importância do "trabalho de parceria", conceito cunhado pela pesquisadora como um trabalho imbricado, sustentando num movimento dialógico e que produz sentidos para todos os envolvidos. Segundo Cassão (2019, p. 254):

Trabalho de parceria: é dedicado. Não acontece por imposição, mas sim pela disposição em querer fazer junto. Exige uma mudança de olhar com relação ao que é seu e o que pode ser nosso. É uma compreensão mais complexa de que, para se atingir um objetivo em comum, algumas renúncias terão que ser feitas. É uma abertura à presença do outro no universo singular da sua atuação profissional[...]. Trabalho de parceria pressupõe entrega, envolvimento, dedicação. Mexe com suas percepções sobre como você se vê enquanto docente. Promove reflexão, que resulta em formação.

\footnotetext{
1 Os projetos desenvolvidos foram: "Prática de leitura e literatura e formação de professores" (2014/2015) e "Do exercício de leitura e escrita na formação do professor: horizontes para promover a autoria e o trabalho coletivo" (2016/2017). A coordenadora de ambos os projetos era a segunda autora deste trabalho.

${ }^{2}$ Neste artigo não aprofundamos estas perspectivas teórico-metodológicas, já que o nosso foco é a socialização dos estudos desenvolvidos.
} 
O trabalho de parceria, nesta concepção, está sustentado em quatro princípios (encontros, palavras, tempos e experiência), contemplando assim a dimensão formativa desse movimento de parceria.

Para ampliar o entendimento acerca do trabalho docente pelo viés da colaboração e parceria, Cassão (2019) também realizou levantamento bibliográfico de periódicos na área de avaliação em educação, com classificação no estrato A1 (QUALIS CAPES). O minucioso levantamento da produção científica realizado pela referida autora na sua pesquisa objetivou sistematizar e compreender os diferentes conceitos que circulam ao tratar da temática da parceria no contexto educativo já que, em princípio, há diversidade de conceitos que se apresentam como similares e, ainda, nem sempre explicitam os referenciais teóricos que os sustentam. No processo de sistematização dos artigos, a autora também mapeou produções que socializassem práticas de trabalho docente na linha do "trabalho de parceria" (CASSÃO, 2019), de um trabalho que não é simples de ser realizado, mas que é potente e, por isso, merece ser problematizado no contexto da formação de professores.

Este trabalho apresenta a sistematização do levantamento bibliográfico realizado e que objetivou compreender o que circula no contexto acadêmico acerca da temática da parceria e da colaboração no campo da formação de professores.

\section{PERCURSO METODOLÓGICO}

$\mathrm{Na}$ busca por ampliar o entendimento acerca do trabalho docente pelo viés da colaboração e parceria foi realizado um levantamento bibliográfico (GIL, 2002) com o intuito de mapear pesquisas existentes na área da educação que pudessem contribuir para ampliar o entendimento das questões acima referidas.

O recorte temporal para escolha dos artigos foi o quadriênio QUALIS/CAPES de 2013 a 2016; foi considerada a área de avaliação: educação; Qualis: A1. Foram considerados os artigos redigidos em língua portuguesa, publicados no Brasil e disponibilizados online (gratuita). Não fizeram parte do levantamento: revistas temáticas (exceto as com tema parceria e ou/trabalho coletivo); resenhas; entrevistas e traduções.

A escolha pelo extrato A1 da Qualis/CAPES teve a intencionalidade de observar em que medida, nesse segmento, são valorizados artigos que tratassem da constituição da parceria em sala de aula como instância formativa. Nesse processo de mapear os artigos, também se pretendia observar o referencial teórico que sustentava tais discussões.

As palavras-chave escolhidas para fazer o levantamento foram: parceria; trabalho coletivo; trabalho colaborativo; trabalho cooperativo; trabalho em conjunto e coletividade. Tais palavras deveriam estar presentes no título, resumo e/ou palavras-chaves.

\section{Seleção dos periódicos A1}

Ao acessar o site que publica a relação de periódicos avaliados como A1, a plataforma disponibilizou uma lista com 121 periódicos. Seguindo os critérios de busca definidos, restaram 12 periódicos dos 121 inicialmente encontrados. Apenas 9\% dos periódicos enquadram-se no recorte estabelecido para a realização deste levantamento bibliográfico.

Abaixo segue uma tabela contendo os 12 periódicos em ordem alfabética, explicitando número de edições e de artigos publicados, bem como aqueles que foram selecionados em função das palavras-chave definidas inicialmente. 
Tabela 1: Periódicos analisados

\begin{tabular}{|c|c|c|c|c|}
\hline \multicolumn{2}{|r|}{ Quadro de periódicos analisados } & \multirow{2}{*}{$\begin{array}{c}\text { Número } \\
\text { de artigos }\end{array}$} & \multirow{2}{*}{$\begin{array}{c}\begin{array}{c}\text { Número } \\
\text { de } \\
\text { edições }\end{array} \\
2013-2016 \\
\end{array}$} & \multirow{2}{*}{$\begin{array}{c}\begin{array}{c}\text { Número de } \\
\text { artigos } \\
\text { escolhidos }\end{array} \\
2013-2016\end{array}$} \\
\hline ISSN & Periódico & & & \\
\hline $1982-5765$ & $\begin{array}{c}\text { Avaliação: revista da avaliação da educação } \\
\text { superior }\end{array}$ & 117 & 12 & 2 \\
\hline $2176-4573$ & Bakbtiniana: revista de estudos do discurso & 124 & 11 & 1 \\
\hline $1980-4415$ & Bolema: boletim de educação matemática (Online) & 160 & 12 & 6 \\
\hline $1980-5314$ & $\begin{array}{c}\text { Cadernos de pesquisa (Fundação Carlos Chagas } \\
\text { Online) }\end{array}$ & 184 & 15 & 6 \\
\hline 1980-850X & Ciência \& educação (Online) & 204 & 16 & 2 \\
\hline $1678-4634$ & Educação e pesquisa & 176 & 16 & 0 \\
\hline $2175-6236$ & Educaşão e realidade edição eletrônica & 223 & 17 & 3 \\
\hline $1982-6621$ & Educação em revista (UFMG Online) & 197 & 16 & 3 \\
\hline $1984-6444$ & Educação (Santa Maria Online) & 179 & 12 & 2 \\
\hline $0104-4060$ & Educar em revista & 255 & 21 & 3 \\
\hline $1809-4465$ & Ensaio - avaliação e políticas públicas em educação & 131 & 16 & 1 \\
\hline $1980-6248$ & Pró-posições (UNICAMP Online) & 120 & 12 & 1 \\
\hline
\end{tabular}

Fonte: CASSÃO (2019)

Abaixo, de forma resumida, encontra-se uma tabela com a quantidade de artigos encontrados no levantamento bibliográfico realizado.

Tabela 2: Quantidade de artigos encontrados por palavra-chave

\begin{tabular}{|c|c|}
\hline PAVAVRA-CHAVE & ARTIGOS ENCONTRADOS \\
\hline Parceria & 13 \\
\hline Trabalho Coletivo & 11 \\
\hline Trabalho colaborativo & 4 \\
\hline Trabalho cooperativo & 0 \\
\hline Trabalho em conjunto & 0 \\
\hline Coletividade & 2 \\
\hline
\end{tabular}

Fonte: CASSÃO (2019)

De um total de 2.026 artigos, 30 apresentaram alguma das palavras-chaves selecionadas ou algum termo equivalente. Em dados quantitativos, esse número equivale a 1,48\% do total de artigos pesquisados. Importante salientar que alguns dos artigos selecionados não traziam no corpo do texto discussões mais aprofundadas acerca do tema "trabalho de parceria" (CASSÃO, 2019).

Segue uma sistematização dos estudos realizados, que serão apresentados através das produções agrupadas por periódico. 


\section{O QUE PROBLEMATIZAM OS ARTIGOS?}

O periódico Avaliação: revista da avaliação da educação superior, pertence à UNISO (Universidade de Sorocaba). O primeiro artigo que traz como título "Avaliação de Redes de Pesquisa e Colaboração" é de autoria de Leite et al. (2014). Em seu resumo o artigo contextualiza a palavra "parceria" articulando o termo ao que chamam de "Redes de pesquisa e colaboração". Segundo as autoras, "[...] as redes de colaboração em pesquisa apresentam especificidades e diferenças nas diferentes áreas do conhecimento" (LEITE et al., 2014, p. 297). Neste estudo o termo "parceria" é entendido pelas autoras como "[...] a intenção de um coletivo em produzir conhecimento" (LEITE et al., 2014, p. 297). Para elas, “[...] a cooperação se dá através de relações e as interações são estimuladas por intenções comuns. De tal sorte que a figura da parceria alcança lugar de destaque" (LEITE et al., 2014, p. 197).

No artigo de Rosa e Lopes (2016), intitulado "Tecendo os fios entre educação e saúde: avaliação do Programa da Residência Multiprofissional em Saúde", o termo parceria aparece no seu resumo e está presente também ao longo do texto para apresentar o Programa de Residência Multiprofissional em Saúde, que é uma parceria entre o Ministério da Saúde e o Ministério da Educação.

Passamos para a revista Bakbtiniana: revista de estudos do discurso. Encontramos apenas um artigo a partir da palavra-chave trabalho colaborativo. Trata-se do artigo intitulado "A dinâmica discursiva na formação de professores: discurso autoritário ou internamente persuasivo?" de autoria de Magalhães, Ninin e Lessa (2014). A partir da perspectiva de Vygotsky, as autoras definem a compreensão do conceito colaborar ou pensar de modo colaborativo. Segundo as autoras, "[...] colaborar envolve um movimento dialético entre participantes, sócio-histórica e politicamente constituídos nos contextos de suas experiências, como intencionalmente responsáveis por ultrapassar limitações, individualismo e alienação" (MAGALHÃES, NININ, LESSA, 2014, p. 132).

Na revista Bolema: boletim de educação matemática (Online) foram encontrados seis artigos: cinco trabalhos com a palavra-chave trabalho colaborativo e um artigo com o termo parceria.

O primeiro artigo de autoria de Sousa (2013), intitulado "Quando professores que ensinam matemática elaboram produtos educacionais, coletivamente, no âmbito do mestrado profissional" traz exatamente a palavra "trabalho coletivo", porém carrega em seu título e resumo a palavra "coletivamente" referenciando um trabalho de criação e desenvolvimento de produtos educacionais, ligados ao ensino da matemática. A autora narra a experiência de professores/pesquisadores que, ao se depararem com situações de dificuldade de aprendizagem em sala de aula, produziram o que Sousa (2013) denominou "produtos educacionais". Sousa afirma que a produção desses materiais pode ser compreendida como um trabalho coletivo já que estiveram envolvidos professores da educação básica (discentes do curso de mestrado profissional), pesquisadores da universidade e licenciandos do curso de licenciatura em matemática. Segundo Sousa (2013), os sujeitos envolvidos nessa produção conseguiram "[...] teorizar sobre os conhecimentos matemáticos que são elaborados com e sobre a sala de aula" (SOUSA, 2013, p. 897).

O segundo artigo da revista Bolema é o "Perscrutando diários de aulas e produzindo narrativas sobre a disciplina estágio supervisionado de um curso de licenciatura em matemática", de autoria de Gonçalves Júnior e Carvalho (2014). Neste artigo, o termo "trabalho colaborativo" aparece nas palavras-chaves do resumo. Aparece também o termo "trabalho conjunto" no corpo do resumo. Os autores narram a experiência de um trabalho entre alunos do estágio supervisionado com o primeiro autor do artigo, ao partilhar aulas de matemática na escola. O professor e os 
DOI: $10.12957 /$ teias. $\%$ Y.45116

estagiários produziram juntos um diário de aula descritivo e reflexivo sobre as aulas observadas e lecionadas que serviram de material de estudo para observar "[...] como eles contribuem para a perspectiva colaborativa vivenciada durante o estágio" (GONÇALVES JÚNIOR, CARVALHO, 2014, p. 777). Ainda acerca desse caderno, os autores afirmam que "[...] compartilhar o caderno permitia completar aquela história, ajudar o outro a continuá-la, colaborar para a consecução dos objetivos em relação à educação matemática dos alunos: nossa corresponsabilidade" (GONÇALVES JÚNIOR, CARVALHO, 2014, p. 790).

Gonçalves Júnior e Carvalho (2014, p. 781) afirmam que Gonçalves Júnior, ao receber os alunos da graduação em suas aulas, "[...] procurava construir um trabalho conjunto com eles, buscava desenvolver uma prática colaborativa". Baseando-se em Fiorentini (2004, p. 59-60), os autores explicitam que,

Num grupo colaborativo, "[...] todos os envolvidos desejam crescer profissionalmente e buscam autonomia profissional"; há um “[...] forte desejo de compartilhar saberes e experiências"; há momentos, durante os encontros, "[...] para bate-papo informal, reciprocidade e comentários sobre experiências e episódios da prática escolar"; os participantes sentem-se "[...] à vontade para expressar livremente o que pensam e sentem e estão dispostos a ouvir críticas e a mudar"; entre os participantes "[...] não existe uma verdade ou orientação única para as atividades", pois cada um "[...] pode ter diferentes interesses e pontos de vista, aportando distintas contribuições e diferentes níveis de participação"; são essenciais para o bom relacionamento do grupo "[...] a confiança e o respeito mútuo"; os participantes "[...] negociam metas e objetivos comuns, corresponsabilizando-se para atingi-los"; "[...] há reciprocidade de aprendizagem” (GONÇALVES JÚNIOR, CARVALHO, 2014, p. 781).

Gonçalves Júnior e Carvalho (2014, p. 791) definem essa experiência de parceria como uma história singular na qual suas "[...] identidades foram sendo negociadas em meio às tensões da prática de investigar e colaborar ao ensinar".

O próximo artigo intitula-se "As narrativas de duas professoras em seus processos de desenvolvimento profissional em educação estatística", de autoria de Lopes (2014). Nesse artigo o termo "trabalho colaborativo" aparece no resumo da obra. A palavra é cunhada para denominar o grupo de trabalho em que duas professoras de matemática do ensino fundamental são participantes. $\mathrm{O}$ artigo foca na potencialidade das narrativas no desenvolvimento profissional das professoras, porém não traz uma definição de trabalho colaborativo.

No levantamento nas edições da Bolema foi encontrado o artigo "Insubordinação criativa: um convite à reinvenção do educador matemático", de autoria de D’Ambrosio e Lopes (2015). O termo presente no resumo do artigo é o "trabalho colaborativo". O foco do estudo é voltado para análise do termo "insubordinação criativa" que, segundo as autoras, acontece quando os educadores matemáticos assumem uma postura de ouvir o seu aluno e os seus colegas, deixando de lado as diretrizes pré-estabelecidas pelas instituições.

Para D’Ambrosio e Lopes (2015, p. 4-5), o "trabalho colaborativo" implica a “[...] formação de um profissional participante, ativo, crítico e responsável, disposto a colaborar com seus pares e a buscar, coletivamente, soluções para os problemas educacionais que emergem em seus espaços pedagógicos". Para tanto, é indispensável na constituição da identidade do professor uma postura colaborativa no seu fazer profissional. Para os mesmos autores, o trabalho colaborativo é "[...] uma possibilidade de os educadores compartilharem ideias, valores e compreensões por meio da 
socialização da elaboração de seus pensamentos e de sua prática" (D’AMBROSIO; LOPES, 2015, p. 11).

Javaroni e Zampieri (2015) escreveram o artigo intitulado "O uso das TIC nas práticas dos professores de matemática da rede básica de ensino: o projeto mapeamento e seus desdobramentos". As palavras "trabalho colaborativo" aparecem no resumo do artigo, usadas para denominar uma rede colaboração: professores que atuaram como colaboradores no projeto mapeamento, que consistia em observar o uso das TIC nas aulas de matemática na educação básica.

O artigo "Ensino de matemática nos anos iniciais: aprendizagens de uma professora no contexto de tarefas investigativas" de Bertini (2015, p. 1201) contempla o termo "trabalho em parceria" no resumo. Tem como foco "[...] a viabilidade do uso de tarefas investigativas no ensino de matemática, nos anos iniciais do ensino fundamental". Apresenta a experiência de uma professora com seus alunos de quarto ano do ensino fundamental de uma escola pública brasileira. Para Bertini (2015), uma relação que envolve colaboração é uma relação que precisa ser construída e, por isso, está sustentada na confiança. Segundo Bertini (2015), o trabalho em parceria é uma instância que possibilita a transformação das práticas da professora. A autora afirma que "[...] o fato de trabalhar junto proporcionou mais do que a superação de algumas dificuldades encontradas pela professora na realização e na condução desse tipo de tarefa; possibilitou, também, o seu desenvolvimento profissional” (BERTINI, 2015, p. 1220).

Os artigos encontrados na revista Bolema tematizam práticas de fazer junto, pensar junto, apontam um caminho produtivo dentro da temática e legitimam a parceria como uma dimensão da constituição profissional docente.

Na revista Cadernos de pesquisa (Fundação Carlos Chagas Online) foram encontrados três artigos com o termo parceria, um deles com o termo trabalho coletivo e outros dois com o termo trabalho colaborativo.

A começar pelo artigo intitulado "Parceria entre ONGs e escolas públicas: alguns dados para reflexão", de autoria de Russo (2013), o termo "parceria" surge logo no título do trabalho. A autora anuncia que o artigo "[...] discute as relações de parceria entre organizações nãogovernamentais e escolas públicas, a partir de um estudo de caso realizado na rede municipal de educação do Rio de Janeiro" (RUSSO, 2013, p. 614). Desse modo, a leitura do resumo já define qual é a empregabilidade da palavra "parceria" na obra: a união de instituições.

O artigo "Trabalho social e intervenção social na França: o estado do conhecimento" de Rullac (2014) também apresenta o termo "parceria" em seu resumo. A designação da palavra, presente no estudo, faz menção à união entre os centros de pesquisa e de estudo para formação e ação social (Prefas) e as universidades francesas.

Escrito por Wittorski (2014), o artigo “A contribuição da análise das práticas para a profissionalização dos professores" não traz nenhum dos termos selecionados como filtro da pesquisa, porém apresenta, em seu resumo, o termo "trocas coletivas". O resumo explicita que o texto analisa a ideia de atividade reflexiva na formação docente. Trata-se de uma pesquisa realizada sobre a metodologia proposta pelo Institut Universitaire de Formationdes Maîtres - IUFM - (Bretanha, França).

Nas palavras do autor: "[...] o que nos interessa diz mais respeito aos processos de transformação individuais e/ou coletivos [...], tentando compreender como esta atividade reflexiva sobre as práticas modifica as atitudes profissionais, os saberes e as identidades" (WITTORSKI, 2014, p. 896). O artigo não define o que seriam essas "trocas coletivas", limitando-se a dizer que "[...] os trabalhos em grupo comprometidos levam a reforçar o efeito da construção de uma identidade coletiva" (WITTORSKI, 2014, p. 904). 
$\mathrm{O}$ artigo "O compartilhamento da educação das crianças pequenas nas instituições de educação infantil", de autoria de Monção (2015), apresenta o termo "parceria" em seu resumo. A palavra está empregada para registrar a relação de parceria estabelecida entre pais e professores em um Centro de Educação Infantil - CEI - da rede municipal de São Paulo. Dos registros das professoras participantes depreendeu-se que a parceria entre elas e os pais esteve mais relacionada à dimensão do cuidado e da higiene das crianças do que no processo de troca e construção de uma parceria no campo educativo.

O artigo "Currículo escolar e deficiência: contribuições a partir da pesquisa-ação colaborativo-crítica" de Magalhães e Soares (2016) não traz o termo "trabalho colaborativo", mas apresenta o termo "ação colaborativo-crítica", o que nos chamou a atenção. Com a proposta de analisar o currículo de uma escola pública relativos à inclusão de estudantes com deficiência, o termo refere-se à metodologia utilizada na pesquisa apresentada no artigo. Segundo as autoras, essa vertente metodológica apresenta um foco que "[...] recai sobre a elucidação do objeto de estudo concomitantemente à imersão no campo de pesquisa e a decorrente aproximação de seus participantes" (MAGALHÃES, SOARES, 2016, p. 1132).

O último artigo da revista Cadernos de pesquisa é de Aciole (2016) e se intitula "Rupturas paradigmáticas e novas interfaces entre educação e saúde". No corpo do texto, o autor utiliza o termo "trabalho colaborativo" e afirma que "[...] à nossa experiência, articulada em ambientes de trabalho colaborativo e interdisciplinar, contrapomos algumas reflexões em torno das ideias de aprendizagem significativa, vista como mais que forma de trabalho em equipe" (ACIOLE, 2016, p. 1175). Isso se justifica pois o foco de pesquisa do autor consistiu em analisar "[...] as novas demandas da saúde que requerem profissionais críticos e reflexivos, competentes para o trabalho em equipe colaborativa e interdisciplinar" (ACIOLE, 2016, p. 1172) no campo da saúde. Aciole (2016, p. 1181) afirma que trabalhar colaborativamente é um entrave na área pesquisada: "Tanto quanto aprender a trabalhar junto, uma equipe de saúde precisa transformar a ação cotidiana feita em conjunto num dispositivo de mediação que dê suporte à aprendizagem interativa e se torne intencional".

No acervo da Ciência \& educação (Online) foram encontrados dois artigos vinculados ao termo trabalho coletivo.

O artigo "Análise de uma proposta colaborativa de formação continuada de professores de ciências da perspectiva do desenvolvimento profissional docente" de autoria de Urzetta e Cunha (2013) contem no resumo o termo "processo coletivo e colaborativo". As autoras investigaram "[...] a possibilidade de desenvolvimento profissional, por meio da análise de uma proposta coletiva de formação continuada de professores de ciências do ensino fundamental" (URZETTA, CUNHA, 2013, p. 842). O termo surge na pesquisa com vistas a salientar o percurso vivido por um grupo de professores no processo de construção de saberes coletivos. O termo "colaborativo" foi empregado para dizer da parceria entre docentes da rede municipal de ensino, professores pesquisadores dos conteúdos específicos e pedagógicos da Universidade Federal de Uberlândia, e alunos da graduação e pós-graduação. Segundo as autoras, o "[...] estudo apontou para a necessidade de que o desenvolvimento profissional seja concebido como um processo coletivo colaborativo, consistindo em possibilitar, aos professores, a construção de novas teorias e novas práticas pedagógicas” (URZETTTA, CUNHA, 2013, p. 856).

O segundo artigo da referida revista, "Sentidos e significados de problema e problematização em um processo de (re)planejamento coletivo de uma situação de estudo", é de autoria de Machado, Marques e Silva (2016). O trabalho apresentou o termo "construção coletiva" 
nas palavras-chaves. As autoras utilizam esse termo para registrar a construção coletiva do currículo na rede de ensino de Ijuí, RS.

Segundo as referidas autoras, as SE (situações de ensino) - objeto de estudo delas mostraram uma construção conjunta do currículo na qual " [...] os professores da universidade, da escola e os licenciandos possam aprender e constituir-se como docentes, num constante processo de (re)significação de suas práticas” (MACHADO, MARQUES, SILVA, 2016, p. 39).

Passamos para a revista Educação e pesquisa. Em seu acervo não foi encontrado nenhum artigo que possuísse, no título, resumo ou palavras-chaves, os termos selecionados para busca. Nem houve registros de termos similares como ocorreu em outros periódicos.

$\mathrm{Na}$ revista Educação e realidade edição eletrônica foram encontrados dois artigos com o termo parceria e um artigo com o termo coletividade.

No artigo "Pibid Diversidade e a formação de educadores do campo", de Sant'Anna e Marques (2015), os autores discutem a formação docente da educação básica brasileira, enfatizando a emergência do diálogo entre os processos formativos e o contexto das escolas públicas. O termo que se apresenta no resumo é "parceria" e apenas aparece aí. O artigo foca na união do Pibid Diversidade com os sujeitos do campo, mas não aprofunda o termo, nem apresenta experiência de trabalho de parceria.

O artigo "A linguagem movimento na educação de bebês para a formação de professores", de Garanhani e Nadolny, (2015) objetivou discutir estratégias formativas que possibilitam a reflexão dos professores acerca dos saberes da linguagem movimento no contexto da educação infantil. Aparece o termo "parceria" para referenciar a união entre os centros municipais de educação infantil de Curitiba (Paraná) e o projeto de formação de professores Educamovimento: saberes e práticas na educação infantil da UFPR (2008-2013).

No artigo "A Dimensão Estética na Aprendizagem: desocultando pontos cegos”, de Freitas (2016), aparece o termo "coletividade" no resumo e faz referência à percepção e o comportamento dos indivíduos em relação à coletividade. $\mathrm{O}$ foco do trabalho recai sobre a instância estética na educação, em especial sobre o olhar sensível na aprendizagem. Com um discurso teórico pautado em Walter Benjamin, o termo é empregado para designar as experiências coletivas (sociedade e cultura). Não há discussão do termo no contexto de práticas de sala de aula.

$\mathrm{Na}$ revista Educação em revista (UFMG. Online) encontramos: um artigo que contempla o termo parceria, um artigo com o termo trabalho coletivo e um artigo com o termo trabalho colaborativo.

No artigo "Um esboço crítico sobre 'parceria' na formação de professores", de autoria de Mateus (2014), o termo "parceria" aparece desde o título e perpassa todo trabalho. O mesmo objetivou investigar iniciativas adotadas pelo governo federal no campo da formação de professores entre 2007-2013 tendo como foco o "[...] Programa Institucional de Bolsa de Iniciação à Docência (Pibid), no qual se realiza o conceito de parceria no cenário educacional como forma de governança sobre práticas de formação de professores" (MATEUS, 2014, p. 355). A autora afirma que, por um lado, o Programa pode ser considerado como "[...] criação de espaço híbrido com potencial transformador" (MATEUS, 2014, p. 355) e, por outro lado, nos provoca ao explicitar que se trata de "[...] deslocamentos artificiais, não previstos e não objetivados em muitas das instituições de ensino envolvidas e, por essa razão, com potencial regulador" (MATEUS, 2014, p. 355). O artigo traz um panorama histórico do termo "parceria", apresentando os três modelos definidos por pesquisadores da área ao longo dos anos: a parceria complementar; a parceria colaborativa e a parceria conduzida pela IES. Interessa-nos a descrição de parceria colaborativa que, segundo a autora, "[...] caracteriza-se pelo compromisso com um programa educacional que 
permita aos licenciandos lidar com diferentes formas de conhecimento advindos da escola, da universidade e de outros contextos de relevância" (MATEUS, 2014, p. 359). Sobre esse modelo também se pode afirmar que "[...] os participantes criam oportunidades para trabalhar juntos as etapas de planejamento, execução e discussão crítica das práticas pedagógicas, valorizando e reconhecendo como legítimas as diferenças" (MATEUS, 2014, p. 359).

Mateus (2014, p. 359) afirma que, independente do modelo, a parceria “[...] não é um mero conceito organizacional, mas uma prática que incorpora importantes dimensões epistemológicas e pedagógicas". Pedagogicamente falando, segundo a referida autora, as parcerias “[...] impõem arranjos próprios que impactam não somente naquilo que os participantes aprendem, mas, igualmente, nos modos como aprendem" (MATEUS, 2014, p. 359).

No acervo da revista Educação em revista (UFMG. Online) encontramos o artigo intitulado "Aprendizagens profissionais de professores dos primeiros anos participantes num estudo de aula", de autoria de Baptista et al. (2014). O termo encontrado foi "trabalho colaborativo". O artigo compartilha a experiência de cinco professoras que trabalharam colaborativamente e conseguiram identificar a potencialidade formativa desse movimento. Segundo os autores, a narrativa das professoras "[...] revelaram que houve um compromisso de todas as professoras envolvidas, possibilitando a concretização do estudo de aula, que envolveu uma análise conjunta de várias situações” (BAPTISTA et al., 2014, p. 75). Para eles, a dimensão colaborativa permitiu às professoras reconhecerem que "[...] houve um aumento da confiança, levando as cinco professoras a arriscar e experimentar novas situações” (p. 75). Isto nos leva a pensar que trabalhar em conjunto movimenta e encoraja a arriscar práticas que, possivelmente, de modo individual, não seriam viáveis.

Outro artigo encontrado foi o de Boy e Duarte (2014) intitulado "A dimensão coletiva do trabalho docente: uma experiência em duas escolas municipais de Belo Horizonte". Achamos dois termos vinculados à busca por palavras-chave: "trabalho coletivo" e "trabalho colaborativo", ambos contidos nas palavras-chaves do artigo.

O artigo tem por objetivo apresentar "[...] a síntese dos resultados de uma pesquisa sobre o trabalho coletivo entre docentes da rede pública municipal de Belo Horizonte" (BOY, DUARTE, 2014, p. 81). A leitura do artigo permitiu observar que os autores consideram o "trabalho colaborativo" uma instância do "trabalho coletivo". Para eles, trabalho colaborativo contempla as práticas interativas entre mais de dois profissionais do ensino que possuem um mesmo estatuto, atuam sobre diferentes objetos e assumem a responsabilidade coletiva por esse tipo de trabalho. Quando existe um trabalho de ordem colaborativa, os envolvidos "[...] se apoiam mutuamente, visando atingir objetivos comuns negociados pelo coletivo. Estabelecem relações que tendem a não hierarquização, à liderança compartilhada, à confiança mútua e à corresponsabilidade pela condução das ações" (BOY, DUARTE, 2014, p. 86). Acerca do termo sobre o termo "trabalho coletivo", Boy e Duarte (2014, p. 85), afirmam com base em Varani (2005) que, “[...] a simples junção de trabalhadores da educação no ambiente escolar não leva ao trabalho conjunto, principalmente se ocorre a segregação de tarefas, de forma que cada um execute uma parte". Ainda os autores, com base em Tardif e Lessard (2005), e, Fullan e Hargreaves (2001), explicitam que alguns dos docentes de sua pesquisa definem o termo como "colaboração para o cumprimento de tarefas" ou "colaboração confortável", na qual se "[...]restringem aos aspectos práticos, imediatos e de curto prazo que abarcam o trabalho docente, como o apoio pedagógico dado ou recebido de um colega, o planejamento do ensino, a construção e a preparação de material pedagógico" (BOY, DUARTE, 2014, p. 91). Os autores explicitam a complexidade de assumir o trabalho coletivo já que, para além dos aspectos pedagógicos (partilha de poder, participação na gestão, criação de 
projeto pedagógico e organizacional comum, partilha do saber, troca de experiências, formação democrática do aluno), requer também outras condições para efetivamente poder realizar esse movimento.

$\mathrm{Na}$ revista Educaşão (Santa Maria. Online) foram encontrados: um artigo com palavra-chave parceria e um artigo com palavra-chave trabalho colaborativo. O primeiro artigo escrito por Gevaerd (2015) intitulado "Ensino de história na perspectiva da educação histórica: o caso da rede municipal de Curitiba" traz a discussão sobre a qualidade do ensino de história na rede municipal da cidade de Curitiba/PR. O termo "parceria" pode ser lido no resumo e registra a união entre Rede Municipal de Ensino de Curitiba e a Universidade Federal do Paraná/Laboratório de Pesquisa em Educação Histórica (LAPE-DUH).

O outro artigo é de Givigi et al. (2016), intitulado "O trabalho colaborativo na escola: o uso da tecnologia assistiva". O termo "trabalho colaborativo" está presente no título, no resumo e nas palavras-chaves do estudo. O manuscrito discute "[...] o processo de escolarização dos sujeitos com deficiência a partir de ações-intervenções realizadas na escola, possibilitadas pelo trabalho colaborativo" (GIVIGI et al., 2016, p. 359). Observamos que os autores cunham o termo relacionando-o com a metodologia de trabalho que, de acordo com os autores, "[...] movimentou as escolas para um novo eixo de ação frente aos alunos com deficiência" (GIVIGI et al., p. 370). Segundo os autores, o trabalho pautado na colaboração permitiu recolocação do lugar que o aluno com deficiência ocupava na escola, "[...] rompendo com o dogma da homogeneidade, sendo consolidadas novas relações entre professor, escola e aluno, bem como o acesso ao conteúdo e novas possibilidades de construção da leitura e da escrita" (GIVIGI et al, 2016, p. 371).

Na revista Educar em revista, vinculada à UFPR (Universidade Federal do Paraná), foram encontrados dois artigos considerando a palavra-chave parceria e um artigo considerando a palavrachave trabalho colaborativo. Trazemos o artigo "As práticas pedagógicas de trabalho com relações étnico-raciais na escola na perspectiva de Lei 10.639/2003: desafios para a política educacional e indagações para a pesquisa" de Gomes e Jesus (2013). Os autores socializam estudo avaliativo da legislação nacional sobre a lei citada no título. Nele, a palavra "parceria" consta do resumo para registrar a união da Secretaria de Educação Continuada, Alfabetização, Diversidade e Inclusão (SECADI/MEC) com a Representação da UNESCO no Brasil e coordenada pelo Programa de Ações Afirmativas na UFMG.

O artigo "Uma proposta de formação em contexto para as professoras de uma creche municipal de Fortaleza", de Lima e Silva (2014), contempla o termo "trabalho colaborativo" ao analisar a contribuição de uma formação na busca de melhor qualidade das práticas pedagógicas das professoras de uma creche municipal em Fortaleza. O termo é tratado no artigo apenas no resumo e nas palavras-chaves. No corpo do texto explicita-se que a metodologia aplicada na pesquisa foi de caráter "pesquisa-ação colaborativa", porém não abarca uma discussão mais dedicada do termo "trabalho colaborativo" em si.

Por último, apresentamos o artigo de Branco e Haracemiv (2015), intitulado "Avaliação do curso de formação de professores no contexto da educação a distância" que discute a avaliação do Curso de Pedagogia à distância da Universidade Federal do Paraná, sob o olhar de seus protagonistas. Encontramos novamente o termo "parceria" que, no contexto do artigo, refere-se à parceria estabelecida entre a Universidade Federal do Paraná (UFPR) e a Universidade Aberta do Brasil. Novamente, por se tratar de parceria entre instituições, não foi realizada leitura mais detalhada.

$\mathrm{Na}$ revista Ensaio - avaliação e políticas públicas em educaşão foi encontrado um artigo com o termo "parceria" intitulado "Currículo e gestão: propondo uma parceria" de Moreira (2013). Trata- 
DOI: $10.12957 /$ teias. $\%$ Y.45116

se de um estudo que observa a experiência finlandesa de construção do currículo traçando um comparativo com a realidade brasileira. O termo parceria não é esmiuçado no corpo do estudo, limitando-se a referenciar a palavra para designar a parceria entre escolas, na figura de seus gestores e das secretarias de educação dos municípios.

Por último, na revista Pro-posições (UNICAMP. Online), foi encontrado um artigo que traz o termo "coletividade". Trata-se do artigo "Recontextualização do currículo integrado na formação médica" de autoria de Heinzle e Bagnato (2015). Sem aprofundar no conceito apresentado, as autoras analisam as propostas de currículo integrado de duas escolas médicas de Santa Catarina e observam que a proposta curricular desafia os discentes a reverem "[...] as relações de coletividade da docência que os atores sociais estabelecem nesse processo" (HEINZLE, BAGNATO, 2015, p. 229).

\section{ALGUMAS CONSIDERAÇÕES}

Ao observarmos os resultados quantitativos do levantamento realizado (30 artigos de um total de 2.026 artigos pesquisados) ficou evidente a pequena quantidade de trabalhos que traz, em seu título, resumo ou palavras-chaves os termos escolhidos para o nosso estudo: parceria; trabalho coletivo; trabalho colaborativo; trabalho cooperativo; trabalho em conjunto e coletividade.

Entretanto, se considerarmos que o termo "trabalho de parceria" (CASSAO, 2019) e seus sinônimos dizem de um fenômeno recente na pesquisa no campo da educação e da formação docente, o fato de ter encontrado artigos que sustentam e legitimam o "fazer junto" como uma instância da constituição docente torna-se algo a ser comemorado.

A pesquisa da qual o presente artigo se inspirou, defende a tese de que um "trabalho de parceria" só é possível quando efetivamente se concebe a formação docente como uma via de mão dupla. Ao mesmo tempo em que a bolsista (professora em formação inicial) está inserida no contexto da escola para aprender junto com a professora em exercício, esta última também aprende. Esses movimentos estão interligados possibilitando que assim, nesse encontro de experiências profissionais, sejam promovidos processos formativos tanto no campo da formação inicial como no da formação continuada de professores.

Destacamos também que o "trabalho de parceria" não é apenas uma atividade puramente profissional. Esse conceito também implica numa atitude de transformação das condições postas no campo da formação docente. Nesse sentido, concordamos com Givigi et al. (2016, p. 371) que entendem que o trabalho coletivo pode configurar-se "[...] como uma possibilidade para que as políticas propostas possam se efetivar. Acreditamos que nele possa haver a abertura de vontades, de projetos coletivos e individuais". E explicitam que ao adotar uma postura e uma prática colaborativa, o professor "[...] ultrapassa um valor ético para epistemologicamente indicar uma ação política" (p. 371). Assim o "trabalho de parceria" afirma também um posicionamento político.

Trabalhos como o de Gonçalves Júnior e Carvalho (2014) contribuem para legitimar propostas de reflexões acerca da estrutura necessária para a realização de um "trabalho de parceria" concreto. Os autores explicitam valores tais como confiança, respeito e coparticipação de todos os sujeitos envolvidos, estando estes sempre abertos ao aprendizado na relação com o outro.

Desse modo, encontrar estudiosos que compartilham de nossas concepções (que consideram o encontro com o outro na sua dimensão formativa) é para nós motivo de grande alegria. Ainda que sejam alguns poucos estudos que tratam do "trabalho de parceria" enquanto componente constitutivo no campo da formação docente em determinados espaços de divulgação 
científica (como as revistas QUALIS A1), consideramos que sua existência já sinaliza abertura e interesse pela temática, que é relevante se pensamos na constituição profissional dos professores.

Para finalizar, entendemos que pensar o "trabalho de parceria" na escola, entre os profissionais da educação - sejam eles gestores, professores em exercício ou professores em formação - implica considerar vários aspectos. Entre eles destacamos a importância de: garantir que a escola se afirme como espaço de acolhimento de todos os que dela participam; conceber a escola como propositora de processos formativos, pautados em relações de confiança, nos quais os sujeitos que participam estejam abertos a dialogar e problematizar questões da vida educativa que compartilham assumindo sua responsabilidade e compromisso perante as decisões tomadas conjuntamente. Uma escola que constantemente revê as relações que institui, avaliando suas concepções, seu fazer e suas práticas. Professores (em exercício e em formação) e gestores que se percebem sujeitos inacabados e, nesse sentido, com possibilidade de se repensar. Sujeitos implicados, sujeitos que no encontro assumem a responsabilidade de fazer do processo educativo um espaço de sentidos para além dos prescritos nos documentos oficiais para a educação em nosso país. Caminho difícil, porém, necessário. Assumir esta perspectiva de trabalho na escola precisa da responsabilidade de cada um de nós, dando passos, expondo pensamentos na ação, delineando percursos que nos levem a construir formas de fazer juntos na escola.

\section{REFERÊNCIAS}

ACIOLE, Giovanni Gurgel. Rupturas paradigmáticas e novas interfaces entre educação e saúde. Cadernos de pesquisa, São Paulo, v. 46, n. 162, p. 1172-1191, dez. 2016.

BAPTISTA, Mónica et al. Aprendizagens profissionais de professores dos primeiros anos participantes num estudo de aula. Educação em revista, Belo Horizonte, v. 30, n. 04, p. 61-79, out./dez. 2014.

BERTINI, Luciane de Fatima. Ensino de Matemática nos anos iniciais: aprendizagens de uma professora no contexto de tarefas investigativas. Bolema, Rio Claro/SP, v. 29, n. 53, p. 1201-1223, dez. 2015. Disponível em http://www.scielo.br/scielo.php?script=sci_arttext\&pid=S0103636X2015000301201\&lng=en\&nrm=iso. Acesso em 30 ago. 2019.

BOY, Lidia Campos Gomes; DUARTE, Adriana Maria Cancella. A dimensão coletiva do trabalho docente: uma experiência em duas escolas municipais de Belo Horizonte. Educação em Revista, Belo Horizonte, v. 30, n. 4, p. 81-104, dez. 2014. Disponível em http://www.scielo.br/scielo.php?script $=$ sci arttext\&pid $=S 0102-$ $46982014000400005 \& \operatorname{lng}=$ en\&nrm=iso. Acesso em 05 jun. 2019.

BRANCO, Veronica; HARACEMIV, Sonia Maria Chaves. Avaliação do curso de formação de professores no contexto da Educação a Distância. Educar em Revista, Curitiba, n. spe1, p. 157-176, 2015. Disponível em http://www.scielo.br/scielo.php?script=sci arttext\&pid=S010440602015000500157\&lng=en\&nrm=iso. Acesso em 20 jul. 2019.

CASSÃO, Pamela Aparecida. Trabalho de parceria: encontros, palavras, experiência e alteridade nos tempos da formação docente. 272 p. Tese (Doutorado em Educação), Instituto de Biociências, Universidade Estadual Paulista (UNESP), Rio Claro/SP, 2019.

D'AMBROSIO, Beatriz Silva; LOPES, Celi Espasandin. Insubordinação Criativa: um convite à reinvenção do educador matemático. Bolema, Rio Claro/SP, v. 29, n. 51, p. 1-17, abr. 2015. Disponível em $\quad$ http://www.scielo.br/scielo.php? script $=$ sci $\operatorname{arttext\& pid=S0103-}$ 636X2015000100002\&lng=en\&nrm=iso. Acesso em 3 jul. 2019. 
GARANHANI, Marinelma Camargo; NADOLNY, Lorena de Fátima. A linguagem movimento na educação de bebês para a formação de professores. Educação e Realidade, Porto Alegre, v. 40, n. 4, p. 1005-1026, dez. $2015.2175-$ Disponível em http://www.scielo.br/scielo.php?script=sci arttext\&pid=S217562362015000401005\&lng=pt\&nrm=iso. Acesso em 21 jul. 2019.

GEVAERD, Rosi Terezinha Ferrarini. Ensino de história na perspectiva da educação histórica: o caso da rede municipal de Curitiba. Educaşão - Revista do Centro de Educação, Santa Maria/RS, v.40, p. 565-577, dez. 2015.

GIL, Antonio Carlos. Como elaborar projetos de pesquisa. São Paulo: Atlas, 2002.

GIVIGI, Rosana Carla do Nascimento; SILVA, Raquel Souza Silva; ALCANTARA, Juliana Nascimento; SOUZA, Thais Alves de; RALIM, Vera Lucia Oliveira. O trabalho colaborativo na escola: o uso da tecnologia assistiva. Educação, Santa Maria/RS, v. 41, p. 357-374, 2016. Disponível em https://periodicos.ufsm.br/reveducacao/article/view/19467. Acesso em 12 jul. 2019.

GOMES, Nilma Lino; JESUS, Rodrigo Ednilson de. As práticas pedagógicas de trabalho com relações étnico-raciais na escola na perspectiva de Lei 10.639/2003: desafios para a política educacional e indagações para a pesquisa. Educar em Revista, Curitiba, n. 47, p. 19-33, mar. 2013.

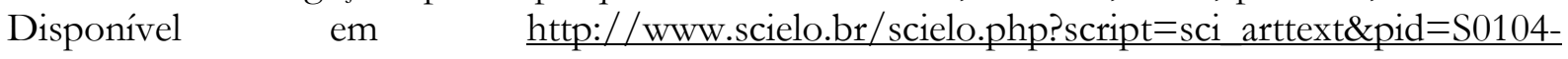
40602013000100003\&lng=en\&nrm=iso. Acesso em 09 ago. 2018.

JÚNIOR, Marcos Antonio Gonçalves; CARVALHO, Dione Lucchesi de. Perscrutando diários de aulas e produzindo narrativas sobre a disciplina estágio supervisionado de um curso de licenciatura em Matemática. Bolema, Rio Claro/SP, v. 28, n. 49, p. 777-798, ago. 2014. Disponível em http://www.scielo.br/scielo.php?script=sci_arttext\&pid=S0103-

636X2014000200777\&lng=en\&nrm=iso. Acesso em 09 nov. 2018.

HEINZLE, Marcia Regina Selpa; BAGNATO, Maria Helena Salgado. Recontextualização do currículo integrado na formação médica. Pro-posições, Campinas/SP, v. 26, n. 3, p. 225-238, dez. 2015. Disponível em http://www.scielo.br/scielo.php?script=sci arttext\&pid=S010373072015000300225\&lng=en\&nrm=iso. Acesso em 31 jul. 2019.

LEITE, Denise et al. Avaliação de redes de pesquisa e colaboração. Avaliação, Sorocaba/SP, v. 19, n. 1, p. 291-312, mar. 2014. Disponível em http://www.scielo.br/scielo.php?script=sci_arttext\&pid=S1414$\underline{40772014000100014 \& \operatorname{lng}=\text { en\&nrm=iso. }}$. Acesso em 31 jul. 2019.

LIMA, Antonia Emanuela Oliveira de; SILVA, Fátima Sampaio. Uma proposta de formação em contexto para as professoras de uma creche municipal de Fortaleza. Educar em Revista, Fortaleza/CE, [S.1.], v. 30, n. 54, p. 293-308, dez. 2014. Disponível em https://revistas.ufpr.br/educar/article/view/36986. Acesso em 09 ago. 2019.

LOPES, Celi Espasandin. As narrativas de duas professoras em seus processos de desenvolvimento profissional em educação estatística. Bolema, Rio Claro/SP, v. 28, n. 49, p. 841-856, ago. 2014.

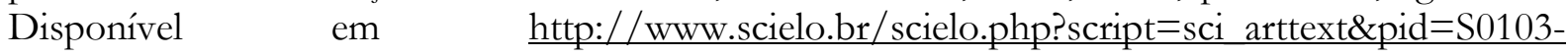
636X2014000200841\&lng=en\&nrm=iso. Acesso em 09 ago. 2020.

MACHADO, Aniara Ribeiro; MARQUES, Carlos Alberto. SILVA, Rejane Maria Ghisolfi da; Sentidos e significados de problema e problematização em um processo de (re)planejamento coletivo de uma situação de estudo. Ciência \& educação., Bauru/SP, v. 22, n. 1, p. 23-42, mar. 2016. Disponível em $\quad$ http://www.scielo.br/scielo.php? script=sci arttext\&pid=S151673132016000100023\&lng=en\&nrm=iso. Acesso em 10 ago. 2019. 
MAGALHAES, Maria Cecília Camargo; NININ, Maria Otilia Guimarães; LESSA, Ângela Brambilla Cavenaghi Themudo Lessa. dinâmica discursiva na formação de professores: discurso autoritário ou internamente persuasivo? Bakbtiniana, São Paulo, v. 9, n. 1, p. 129-147, jul. 2014. Disponível em $\quad \underline{\text { http://www.scielo.br/scielo.php?script }=\text { sci arttext\&pid=S2176- }}$ 45732014000100009\&lng=es\&nrm=iso. Acesso em 12 ago. 2019.

MAGALHÃES, Rita de Cássia Barbosa Paiva Magalhães; SOARES, Marcia Torres Neri. Currículo escolar e deficiência: contribuições a partir da pesquisa-ação colaborativo-crítica. Cadernos de pesquisa, São Paulo, v. 46, n. 162, p. 1124-1147, dez. 2016. Disponível em http://www.scielo.br/scielo.php?script $=$ sci arttext\&pid $=S 0100$ -

15742016000401124\&lng=en\&nrm=iso. Acesso em 31 ago. 2019.

MATEUS, Elaine Fernandes. Um esboço crítico sobre "parceria" na formação de professores. Educação em revista, Belo Horizonte, v. 30, n. 3, p. 355-384, set. 2014. Disponível em http://www.scielo.br/scielo.php?script $=$ sci arttext\&pid $=S 0102-$ 46982014000300016\&lng=en\&nrm=iso. Acesso em 3 abr. 2019.

MONÇÃO, Maria Aparecida Guedes. O compartilhamento da educação das crianças pequenas nas instituições de educação infantil. Cadernos de Pesquisa, São Paulo, v. 45, n. 157, p. 652-679, set. 2015. Disponível em $\quad \underline{h t t p: / / w w w . s c i e l o . b r / s c i e l o . p h p ? s c r i p t ~}=$ sci arttext\&pid=S010015742015000300652\&lng=en\&nrm=iso. Acesso em 9 abr. 2019.

MOREIRA, Antonio Flavio Barbosa. Currículo e gestão: propondo uma parceria. Ensaio: avaliação e políticas públicas em educação, Rio de Janeiro, v. 21, n. 80, p. 547-562, set. 2013. Disponível em http://www.scielo.br/scielo.php?script $=$ sci arttext\&pid $=$ S0104-

40362013000300009\&lng=en\&nrm=iso. Acesso em 9 abr. 2019.

ROSA, Soraya Diniz; LOPES, Roseli Esquerdo. Tecendo os fios entre educação e saúde: avaliação do Programa da Residência Multiprofissional em Saúde. Avaliação, Sorocaba/SP, v. 21, n. 2, p. 637660, jul. 2016. Disponível em http://www.scielo.br/scielo.php?script=sci_arttext\&pid=S141440772016000200637\&lng=en\&nrm=iso. Acesso em 9 abr. 2019.

RULLAC, Stéphane. Trabalho social e intervenção social na França: o estado do conhecimento. Cadernos de pesquisa, São Paulo, v. 44, n. 154, p. 876-890, dez. 2014. Disponível em http://www.scielo.br/scielo.php?script $=$ sci arttext\&pid $=\mathrm{S} 0100-$

15742014000400876\&lng=en\&nrm=iso. Acesso em 10 mar. 2019.

RUSSO, Kelly. Parceria entre ONGs e escolas públicas: alguns dados para reflexão. Cadernos de pesquisa, São Paulo, v. 43, n. 149, p. 614-641, ago. 2013. Disponível em http://www.scielo.br/scielo.php?script $=$ sci arttext\&pid $=\mathrm{S} 0100$ -

15742013000200012\&lng=pt\&nrm=iso. Acesso em 2 ago. 2019.

SANT'ANNA, Paulo Afranio.; MARQUES, Luiz Otávio Costa. Pibid Diversidade e a Formação de Educadores do Campo. Educação e realidade, Porto Alegre, v. 40, n. 3, p. 725-744, set. 2015. Disponível em http://www.scielo.br/scielo.php?script=sci arttext\&pid=S217562362015000300725\&lng=en\&nrm=iso. Acesso em 9 maio 2020.

SOUSA, Maria do Carmo de. Quando professores que ensinam matemática elaboram produtos educacionais, coletivamente, no âmbito do mestrado profissional. Bolema, Rio Claro/SP, v. 27, n. 47, p. 875-899, dez. 2013. Disponível em http://www.scielo.br/scielo.php?script $=$ sci arttext\&pid $=$ S0103636X2013000400009\&lng=en\&nrm=iso. Acesso em 9 ago. 2019. 
URZETTA, Fabiana Cardoso; CUNHA, Ana Maria de Oliveira. Análise de uma proposta colaborativa de formação continuada de professores de ciências na perspectiva do desenvolvimento profissional docente. Ciência \& educação, Bauru/SP, v. 19, n. 4, p. 841-858, 2013.

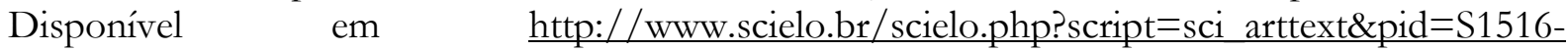
73132013000400005\&lng=en\&nrm=iso. Acesso em 5 maio 2019.

WITTORSKY, Richard. A contribuição da análise das práticas para a profissionalização dos professores. Cadernos de pesquisa, São Paulo, v. 44, n. 154, p. 894-911, out./dez. 2014.

Submetido em setembro de 2019

Aprovado em julbo de 2020

\section{Informações das autoras}

Pamela Aparecida Cassão

Doutora em Educação pela Universidade Estadual Paulista (UNESP), campus Rio Claro.

E-mail: cassaopa@gmail.com

ORCID: https://orcid.org/0000-0001-6630-3360

Link Lattes: http://lattes.cnpq.br/9587537920288654

Laura Noemi Chaluh

Professora do Departamento de Educação e do Programa de Pós-Graduação em Educação do Instituto de Biociências da Universidade Estadual Paulista (UNESP), campus Rio Claro.

E-mail: laura.chaluh@,unesp.br

ORCID: https://orcid.org/0000-0003-0014-7232

Link Lattes: http://lattes.cnpq.br/5879357007917808 